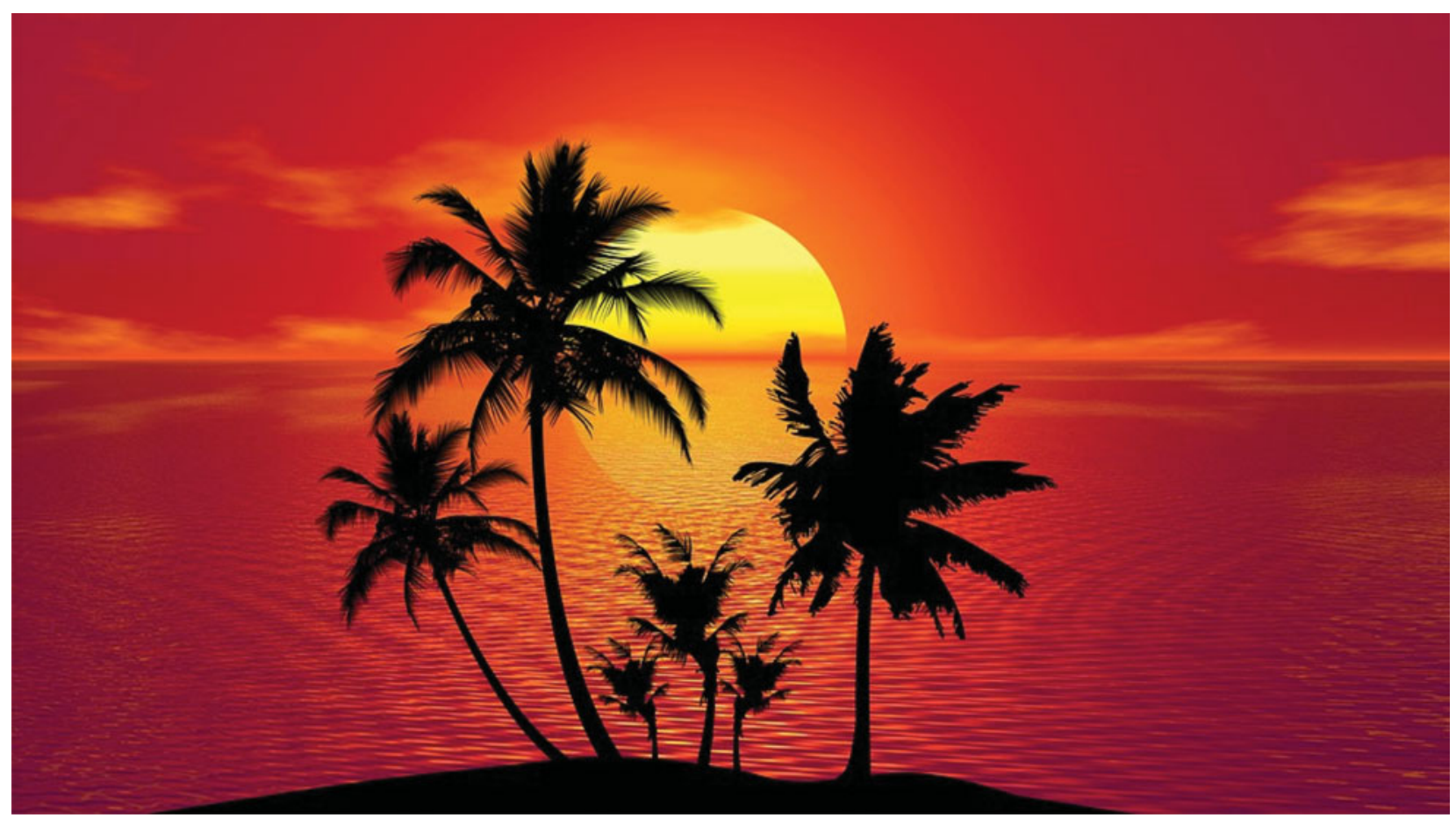

\title{
Editor's Closing Remarks: Tomorrow is here
}

\author{
Robert F. Morgan, Founding Editor
}

In agreement with our publisher, this is our seventh and last year as the online Journal of Tropical Psychology.

In our first year, with publisher Australian Academic Press, and the six subsequent years with Cambridge University Press, all annual volumes held to the same mission and objectives:

Hugely substantial psychological work is being done in tropical zone countries and regions. Journal of Tropical Psychology is specifically circum-global and unites the rapidly growing torrid climate-related nations around the earth in the development and sharing of their psychological discoveries. In addition to the geographical limits of past designated tropical countries, this rapidly expanding torrid or tropical zone could eventually and increasingly include all but the most polar regions. The journal's summary objectives are:

- To share the full range of psychological progress in the growing tropical climate regions
- To disseminate progress in adaptation to the global expansion of tropical climates

- To develop an international network of psychologists working in these regions

In this seventh annual online volume, we have expanded the scope of the journal substantially, above and beyond our regular accepted submissions. We chose a key regional meeting of an international association and, in collaboration with their leadership, to publish their nearly 500 abstracts as well as up to 10 of their judged-best papers. Our choice was the 6th ASEAN Regional Union of Psychological Societies (ARUPS) Congress, held in Bali October 2017 (http:// arups2017.himpsi.or.id/welcome letter-letter/). From this, we anticipated that the conference participants will go on to further develop psychological information sharing networks across the region, a key journal objective.

Yet, this expansion is dwarfed by the rapid expansion of what is considered tropical or, more to the point, torrid 
regions (Harding, 2009, 2016). Our tropical focus on what was once only a piece of global geography increasingly applies to our entire overheating planet, an Earth now that, when seen from space, glows with a hot golden aura from the exponential impact of climate change. It would seem that the entire planet is becoming the torrid zone.

In this tomorrow, we would anticipate both more fully global psychology journals from our international associations (like IAAP, IUPS, ICP) and more clearly focused regional ones (like the Caribbean Journal of Psychology and the Pacific Rim Psychology).

We fall somewhere in-between. Hopefully, in our seven year lifespan, we have been a useful bridge to introducing tropical psychologists and psychology to the global conversation. Jung envisioned a "collective unconscious" for the human family and, in our way, we have done our best to introduce the tropical psychology portion to the profession as more of a 'collective conscious', even if in an online electronic way. Now though, as the Earth accelerates to become entirely a torrid zone, tropical psychology might better be understood as a generic planetary psychology.

I would like to first thank my valiant and unfunded Associate \& Managing Editors. First there was Natasha Riard, a Singaporean psychologist who in her very busy pre-and post-doctoral years stepped forward with me to found the Journal in Singapore. In this we were assisted by Edward Helmes and Sarah Li Wai Soon, as well as a distinguished and diverse volunteer Editorial Board, now numbering 19 reviewers from eight different countries (listed elsewhere in this volume). In subsequent years, Australian psychologists Deborah Graham, and then Denise Dillon, carried the duties of Associate \& Managing Editor inspirationally and effectively, also assisted by Assistant Editors: Wendi Li and Anne Swinbourne. From the Cambridge University Press, we had superb collaboration with Anne Harvey, Amy Hughes, Carol Miller, Sue Tuck, Edward (Ned) Wilson-Eames, and Amy Woolf, among others.

Time is a place. In this place we have shared an oasis of tropical psychology networking. I have enjoyed sharing this temporal oasis with all who have contributed, all who have read, and all who will share or use this material. In another article in this volume (Morgan 2017), I quote a Singaporean slogan: "The future will be better tomorrow." Tomorrow for our journal comes at the close of this volume. It will be a fresh day, ever more torrid, but as yet untouched. What will we do with it?

\section{References}

Harding, S. (2009) Introduction, Torrid Zone Symposium, United Nations Youth Conference, Brisbane.

Harding, S. (2016) A new global dynamic: Recognising the importance of the Tropics. Journal of Tropical Psychology, 6, Cambridge University Press, doi: https://doi.org/10.1017/ jtp. 2016.2

Morgan, R.F. (2017) The future will be better tomorrow. Journal of Tropical Psychology, 7,Cambridge University Press, doi:10.1017/jtp.2017.21-6. 